\title{
MODEL KOMUNIKASI PELAYANAN PUBLIK AKADEMIK DI SLB NEGERI A KOTA BANDUNG
}

\author{
Amida Windari Fitria, Hanny Hafiar, Centurion C. Priyatna \\ Fakultas Ilmu Komunikasi, Universitas Padjadjaran \\ J1.Raya Bandung-Sumedang KM.21 Bandung \\ hannyhafiar@gmail.com
}

\begin{abstract}
Public service is one of the activities that must be carried out by the institution properly. Every institution, including schools, has internal and external publics that need to be served. One of the external publics for SLBN A in Bandung City is the academic public who conducts research, service, and teaching practice for SLB teacher candidates. The intensity of academic public visits is quite high, so excellent public service communication is needed. The purpose of this study was to determine the communication model of academic public service in SLB Negeri A Bandung City. The method used is exploratory case study, with a single case. Data collected by interview, observation and literacy tracking. The informants were chosen purposively consisting of management at the school, teachers, students, parents of students, alumni, and also the academic public itself. The results show that: communicators or parties providing services to the academic public are Administrative, Public Relations, School Principals, $R \& D$ Coordinators and Teachers. The message conveyed is about the communication procedures in academic public services which have seven stages. The media used are face-to-face communication (formal and informal) and media communication (Whatsapp, Telephone, Correspondence and Disposition). The communicant is an academic public including students, lecturers, researchers and observers who carry out the PPL / PPG I PKL program, final research (thesis, thesis and dissertation), non-final research (grants and projects). Academic public feedback is carried out by providing research reports to SLBN A Bandung.
\end{abstract}

Keywords: communication model, public service, academic public, SLBN A Bandung.

\begin{abstract}
Abstrak
Pelayanan publik merupakan salah satu aktivitas yang harus dijalankan lembaga dengan baik. Setiap lembaga, termasuk sekolah memiliki publik internal dan eksternal yang perlu dilayani. Salah satu publik eksternal bagi SLBN A Kota Bandung adalah publik akademis yang melakukan kegiatan penelitian, pengabdian hingga praktik mengajar bagi calon guru SLB. Intensitas kunjungan publik akademik ini cukup tinggi, sehingga dibutuhkan komunikasi pelayanan publik yang prima. Tujuan dari penelitian ini adalah untuk mengetahui model komunikasi pelayanan publik akademik di SLB Negeri A Kota Bandung. Metode yang digunakan adalah studi kasus eksploratif, dengan kasus yang bersifat tunggal. Data dikumpulkan dengan cara wawancara, observasi dan penelusuran literasi. Adapun narasumber dipilih secara purposif yang terdiri dari pihak manajemen di sekolah, guru, siswa, orang rua siswa, alumni, dan juga publik akademik itu sendiri. Hasilnya menunjukkan bahwa: komunikator atau pihak-pihak yang memberikan pelayanan kepada publik akademik adalah Tata usaha, Wakasek Humas, Kepala Sekolah, Koordinator Litbang dan Guru. Pesan yang
\end{abstract}




\section{JURNAL NOMOSLECA}

Volume 5 Nomor 2, Oktober 2019

disampaikan adalah mengenai prosedur komunikasi dalam pelayanan publik akademik yang memiliki tujuh tahapan. Media yang digunakan adalah komunikasi tatap muka (formal dan informal) serta komunikasi bermedia (Whatsapp, Telepon, Surat Menyurat dan Disposisi). Komunikan adalah publik akademik di antaranya mahasiswa, dosen, peneliti dan observer yang melakukan program PPL/PPG/PKL, penelitian tugas akhir (skripsi, tesis dan disertasi), penelitian non tugas akhir (hibah dan proyek). Umpan Balik dilakukan oleh publik akademik dengan memberikan laporan penelitian ke SLBN A Kota Bandung.

Kata kunci: model komunikasi, pelayanan publik, publik akademik, SLBN A Kota Bandung

\section{PENDAHULUAN}

UU RI No 20 Tahun 2003 tentang SISDIKNAS berisi tentang sistem pendidikan nasional yang mampu menjamin pemerataan kesempatan pendidikan, peningkatan mutu serta relevansi dan efisiensi manajemen pendidikan untuk menghadapi tantangan sesuai dengan tuntutan perubahan kehidupan lokal, nasional, dan global sehingga perlu dilakukan pembaharuan pendidikan secara terencana, terarah, dan berkesinambungan

(www.komisiinformasi.go.id, 2003). Maka dari itu kehadiran para publik akademik untuk melakukan peningkatan mutu Pendidikan dengan penelitian-penelitian yang dilakukan di SLB Negeri A Kota Bandung, diharapkan hasilnya dapat bermanfaat bagi sekolah tersebut.

Kerjasama dengan perguruan tinggi merupakan salah satu bentuk komunikasi di SLB Negeri A Kota Bandung. Dengan Perguruan-perguruan tinggi kerjasama juga terus ditingkatkan agar mampu menambah wawasan yang luas bagi peserta didik dan juga memberi kesempatan kepada mahasiswa Program Pengalaman Lapangan (PPL) dari berbagai perguruan tinggi, untuk memiliki bekal pengalaman mengajar sebagai calon guru.

Jumlah mahasiswa yang berasal dari Universitas Pendidikan Indonesia cukup mendominasi publik akademik di SLB Negeri A Kota Bandung karena sebagaian besar mereka memang melaksankan Program Pengalaman Lapangan (PPL) di bidang pengembangan Pendidikan selama 3 bulan dan PPG (Program Pendidikan Profesi Guru) selama 1 tahun. Bahkan ada yang melanjutkan mengerjakan tugas akhir dengan mengambil objek penelitiannya di SLB Negeri A Kota Bandung. Setiap hari para mahasiswa UPI mendampingi siswa tunanetra di lingkungan sekolah.

Sekolah merupakan suatu tempat untuk mencari ilmu. Sekolah memberikan kontribusi penting untuk kemajuan sebuah negara karena sekolah merupakan tempat mendidik generasi-generasi baru yang siap menghadapi tantangan yang besar dan nyata di dunia ini. Sekolah dapat membentuk kepribadian siswa-siswi untuk memiliki karakter positif. Sehingga dapat beradaptasi dengan lingkungan sekitar. Selain itu sekolah merupakan tempat belajar melakukan segala kegiatan mulai dari membaca, menulis dan kegiatankegiatan lain yang masih berada dalam koridor dunia Pendidikan. Kegiatan membaca, akan membuka jendela dunia yang memberikan banyak pengetahuan tentang segala hal. Begitu pentingnya keberadaan sekolah saat ini. Sehingga membutuhkan manajemen atau 
pengelolaan yang berkualitas agar dapat melakukan perannya secara optimal.

Manajemen humas dalam pendidikan merupakan mediator yang berada di antara pimpinan sekolah dengan publiknya. Selanjutnya, aktivitas tugas humas adalah mengelola komunikasi antara organisasi dengan publiknya. Jadi dapat dikatakan bahwa humas (public relations) adalah aktivitas yang menghubungkan antara organisasi dengan masyarakat (public) demi tercapaianya tujuan organisasi dan harapan masyarakat dengan produk yang dihasilkan. Berdasar pengertian tersebut, maka maksud disusunnya program kerja Wakil Kepala Sekolah/PP urusan Hubungan Masyarakat adalah mampu menjembatani keterlibatan seluruh anggota masyarakat sekolah, guru, karyawan, siswa, orang tua, lingkungan, perguruan tinggi dan lembaga pemerintah dan swasta untuk ikut peduli dalam mengoptimalkan kemampuan dan kerja sama sesuai dengan kemampuannya masing-masing, dan membantu kepala sekolah dalam kegiatan pengelolaan sekolah. (Rahmad, 2016: 26)

SLB Negeri A kota Bandung menjadi sekolah layanan pendidikan khusus bagi penyandang disablitas khususnya tunanetra yang tertua di Indonesia bahkan se-Asia Tenggara. Hal ini tentu hal yang membanggakan dengan memiliki sekolah yang menjadi piooner perkembangan pendidikan di Asia Tenggara. Sejak berdirinya di tahun 1901, artinya sudah seabad lebih SLB Negeri A kota Bandung mengalami berbagai dinamika di tingkat regional, nasional maupun internasional (slbnabandung.sch.id, 2018). SLB Negeri A Kota Bandung terletak bersamaan di kompleks Panti Sosial Bina Netra (PSBN)
"Wyata Guna" yang beralamatkan di Jalan Pajajaran No. 52 Kota Bandung.

Kehadiran SLB Negeri A Kota Bandung menjadikan wadah bagi para tunanetra yang berada di lingkungan Bandung untuk dapat beraktivitas sesuai dengan kebutuhan khusus dan fasilitas khusus yang sudah disiapkan oleh Lembaga ini. Sehinga para tunanetra mendapatkan bimbingan pengetahuan dasar Pendidikan, fisik, mental sosial pelatihan keterampilan, resosialisasi dan bimbingan lanjut bagi para penyandang tunanetra agar mampu mandiri dan berperan aktif dalam kehidupan bermasyarakat. Sekaligus memberikan pelayanan prima kepada publik yang memiliki kepentingan dengan lembaga, termasuk publik akademik. Berdasarkan fokus penelitian tersebut maka pertanyaan penelitian yang menjadi tujuan dilakukannya riset ini adalah Bagaimana model komunikasi pelayanan publik akademik yang dilakukan SLB Negeri A Kota Bandung?

Teori yang digunakan dalam penelitian ini adalah teori Konstruksi Sosial Atas Realitas. Istilah konstruksi sosial atau realitas menjadi terkenal sejak dipernalkan pertama sekali oleh Peter L. Berger dan Thomas Luckmann melalui buku mereka berjudul: The Social Construction of Reality, a Treatise in the Sociological of Knowledge pada tahun 1996. Teori ini membahas proses yang digunakan orang untuk bersama-sama mengkonstruksi pemahaman tentang dunia. Pendukung teori ini mengasumsikan bahwa:

"Makna dikembangkan dengan berkoordinasi dengan orang lain, bukan dikembangkan sendiri-sendiri oleh individu. Karena itu, interaksi sosial 
menjadi bagian dari penyusunan tatanan sosial (Littlejohn \& Foss, 2016)"

Individu menciptakan secara trus menerus suatu realitas yang dimiliki dan dialami Bersama secara subjektif. Realitas sosial tidak berdiri sendiri tanpa kehadiran individu, baik di dalam maupun di luar realitas tersebut. Realitas tersebut memiliki makna, manakala realitas sosial dikonstruksi dan dimaknakan secara subjektif oleh individu lain sehingga memantapkan realitas itu secara objektif. Individu mengonstruksi realitas sosial dan merekonstruksikan dalam dunia realias, memantapkan realitas itu berdasarkan subjektivitas individu lain dalam institusi sosialnya.

Konstruktivisme dilihat sebagai sebuah kerja kognitif individu untuk menafsirkan dunia realitas yang ada karena terjadi relasi sosial antara individu dengan lingkungan atau orang di sekitarnya. Kemudian individu membangun sendiri pengetahuan atas realitas yang dilihatnya itu berdasarkan pada struktur pengetahuan yang telah ada sebelumnya. Hal inilah yang kemudian dikatakan sebagai skema/schemata. Konstuktivisme inilah yang oleh Berger dan Luckmann disebut dengan konstruksi sosial.

Asumsi dasar dari Teori Konstruksi Sosial Berger dan Luckmann ini adalah: (1) Realitas merupakan hasil ciptaan manusia kreatif melalui kekuataan konstruksi sosial terhadap dunia sosial di sekelilingnya, (2) Hubungan antara pemikiran manusia dan konteks sosial tempat pemikiran itu timbul, bersifat berkembang dan dilembagakan, (3) Kehidupan masyarakat itu dikonstruksi secara terus menerus, (4) Membedakan antara realitas dengan pengetahuan. Realitas diartikan sebagai kualitas yang terdapat di dalam kenyataan yang diakui sebagai memiliki keberadaan (being) yang tidak bergantung kepada kehendak kita sendiri. Sementara pengetahuan didefinisikan sebagai kepastian bahwa realitas-realitas itu nyata (real) dan memiliki karakteristik yang spesifik. Selain itu mereka pun mengatakan bahwa dialektika yang terjadi antara individu mencipatakan masyarakat dan masyarakat menciptakan individu.

Proses dialektika ini berlangsung dalam proses dengan tiga "moment" simultan. Pertama, eksternalisasi (penyesuaian diri) dengan dunia sosiokultural sebagai produk manusia. Kedua, objektivasi, yaitu interaksi sosial yang terjadi dalam dunia intersubyektif yang dilembagakan atau mengalami proses institusionalisasi. Sedangkan ketiga, internalisasi, yaitu proses di mana individu mengidentifikasikan dirinya dengan lembaga-lembaga sosial atau organisasi sosial tempat individu menjadi anggotanya. Tiga proses ini terjadi di antara individu satu dengan individu lainnya dalam masyarakat. Substansi teori dan pendekatan konstruksi sosial atas realitas Berger dan Luckman adalah proses simultan yang terjadi secara alamiah melalui bahasa dalam kehidupan sehari-hari pada sebuah komunitas primer dan semi-sekunder.

Peneliti menggunakan teori ini dikarenakan teori ini membahas proses yang digunakan orang untuk bersama-sama mengkonstruksi pemahaman tentang dunia. Hal ini sesuai dengan tujuan penelitian ini yakni untuk mengetahui model komunikasi pelayanan publik akademik yang dapat dilakukan SLB Negeri A Kota Bandung.

Teori ini digunakan untuk mengetahui pemahaman prosedur pelayanan bagi narasumber sesuai dengan konsep dasar teori ini yakni manusia atau masyarakat akan memiliki suatu 
pemahaman bersama atas suatu realitas, realitas disini yakni komunikasi dalam pelayanan kepada publik akademik. Jadi, pemahaman prosedur pelayanan haruslah dipahami bersama khususnya warga sekolah dan publik akademik, termasuk didalamnya semua narasumber dalam penelitian ini. Bagaimana pemahaman prosedur pelayanan itu diberikan ketika narasumber berada dalam satu kesatuan (warga SLB Negeri A Kota Bandung). Salah satu konsep yang ada dalam teori ini yakni proses internalisasi yaitu proses yang mana individu mengidentifikasikan dirinya dengan lembaga-lembaga sosial atau organisasi sosial tempat individu menjadi anggotanya, juga dijadikan landasan dalam penelitian ini untuk akhirnya akan memunculkan model komunikasi dalam pelayanan di SLB Negeri A Kota Bandung.

Adanya pemahaman bersama yang berada dalam benak subjek penelitian, yang tentu saja mereka dapatkan dari adanya interaksi bersama (berdasarkan teori ini terjalin karena adanya interaksi dari pengalaman yang sama) akan membuat individu atau subjek penelitian itu lebih memahami mengenai prosedur pelayanan ini, yang nantinya tentu akan membantu dalam menjawab pertanyaanpertanyaan penelitian yang diajukan.

Pemahaman tentang pelayanan berdasarkan versinya inilah yang pada akhirnya membentuk realitas sosial yang baru akan konsep dan arti pelayanan. Hal ini disebut ekstenalisasi. Hasil dari proses eksternalisasi yang dilakukan oleh para narasumber secara perlahan akan terlegitimasi secara institusional maupun sosial, maka terjadilah objektivitas berupa porses penerimaan bersama atas pemahaman pelayanan bagi SLB Negeri A Kota Bandung serta lingkungan sekitar yang berinteraksi dengan sekolah tersebut.
The social construction of reality theory berasumsi bahwa realitas sosial (masyarakat) dikonstruksi. Dalam penelitian di dunia Public Relations dapat memberikan pengertian hubungan antara kata-kata dan isu-isu, serta antara content dan pemaknaan. Akademisi Public Relations dan komunikasi mengkaji konstruksi realitas sosial melalui penelitian simbol dan makna dalam substansi pesanpesan yang dikonstruksi dan disampaikan oleh organisasi kepada stakeholders kunci. Hal ini dilakukan melalui pesan-pesan (simbol-simbol) bahwa orang-orang membuat, mengelola dan menyampaikan interpretasi realitas melalui interaksi sosial, yang mana masyarakat melakukan fungsinya oleh pembagian dan pemberian makna untuk realitas secara fisik dan sosial. Akhirnya, pembagian memberikan dasar pijakan bagi perilaku koperatif melalui realitas social. Dari sebuah perspektif Public Relations yang tergabung dalam perspektif konstruksionis sosial, mendalaminya pada tradisi retorika, Public Relations bisa membantu individu dan kelompok mulai dari persiapan untuk memahami sebagai pengambil keputusan kritis dan menggunakan masyarakat yang dikonstruksi, sampai pemilihan nilai yang dianut (Ardianto, $2010: 156$ )

\section{METODE PENELITIAN}

Paradigma yang digunakan dalam penelitian ini adalah paradigma konstruktivisme. Dimana tujuan dari penelitian ini adalah untuk memahami secara dalam mengenai prosedur dan model komunikasi dalam pelayanan di SLB Negeri A Kota Bandung terhadap publik akademik dengan menggunakan prinsip dasar konstruktivisme. Paradigma konstruktivisme memandang realitas kehidupan sosial 


\section{JURNAL NOMOSLECA}

bukanlah realitas yang natural, tetapi terbentuk dari hasil konstruksi. Hal ini dijelaskan oleh (Ardianto, 2010 : 154) yang menyatakan bahwa pengetahuan manusia adalah konstruksi yang dibangun dari proses dengan interaksinya dengan dunia objek material. Pengalaman manusia terdiri dari interpretasi bermakna terhadap kenyataan dan bukanlah reproduksi kenyataan. Dengan demikian dunia muncul dalam pengalaman manusia secara terorganisasi dan bermakna. Keberagaman pola konseptual/kognitif merupakan hasil dari lingkungan historis, cultural dan personal yang digali secara terus menerus.

Pada penelitian ini, realitas yang diteliti merupakan proses konstruksi mental yang bersifat emik dan spesifik berdasarkan pemahaman pelayanan SLB Negeri A Kota Bandung terhadap publik akademik serta implementasi komunikasi pelayanan publik yang dilakukan oleh SLB Negeri A Kota Bandung. Dengan demikian, kepercayaan dasar yang melandasi atau paradigma yang digunakan dalam penelitian ini adalah paradigma kosntruktivisme.

Alasan peneliti menggunakan paradigma ini adalah karena dalam penelitian "Komunikasi dalam Pelayanan di SLB Negeri A Kota Bandung Terhadap Publik Akademik" memiliki tujuan untuk menemukan hasil temuan baru berupa hasil konstruksi tentang pemahaman para narasumber atau individu terkait mengenai pelayanan sendiri serta berupa implementasi komunikasi publik apa saja yang menyebabkan kurang optimalnya pelayanan agar nanti dijadikan bahan evaluasi untuk kedepannya

Penelitian ini menggunakan metode kualitatif. Mengikuti paradigma studi kasus. Studi kasus merupakan salah satu jenis pendekatan kualitatif yang menelaah sebuah "kasus" tertentu dalam konteks atau setting kehidupan nyata kontemporer. Peneliti studi kasus bisa memilih tipe penelitiannya berdasarkan tujuan, yakni studi kasus instrumental tunggal (yang berfokus pada satu isu atau persoalan tertentu), studi kasus kolektif (yang memanfaatkan beragam kasus untuk mengilustrasikan satu persoalan penting dari berbagai perspektif), studi kasus intrinsik (yang fokusnya adalah pada kasus itu sendiri, karena dianggap unik atau tidakbiasa). Prosedurnya utamanya melibatkan sampling purposeful (untuk memilih kasus yang dianggap penting), yang kemudian dilanjutkan dengan analisis holistic atas kasus tersebut melalui deskripsi detail atas pola-pola, konteks dan setting di mana kasus itu terjadi.(Creswell, 2013: 136).

\section{HASIL DAN PEMBAHASAN}

\section{Model Komunikasi Pelayanan Publik Akademik Yang Dapat Dilakukan Slb Negeri A Kota Bandung}

Komunikasi merupakan salah satu kemampuan yang harus dimiliki oleh tiap individu atau karyawan. Salah satu yang terpenting adalah komunikasi interpersonal yaitu kemampuan tiap individu atau karyawan untuk berkomunikasi baik dengan pimpinan, rekan kerja dan juga para publik (Yanti, 2013 : 40). Adanya publik akademik untuk penelitian ataupun melakukan kegiatan dalam rangka pengembangan Pendidikan siswa SLB Negeri A Kota Bandung, maka perlu kiranya sekolah untuk terus meningkatkan pelayanannya terhadap publik akademik tentunya dengan komunikasi yang baik. Apabila komunikasi yang baik maka akan terjalin hubungan yang baik antara lembaga dengan publiknya. Di SLBN A Kota Bandung, pelayanan publik terhadap publik akademik berada pada kordinasi 
Wakil Kepala Sekolah urusan Hubungan Masyarakat, yang tupoksinya sebagai berikut:

Tabel 1 Tupoksi Wakasek Humas SLBN A Kota Bandung

\begin{tabular}{|c|}
\hline TUGAS POKOK DAN FUNGSI \\
(TUPOKSI) \\
WAKASEK URUSAN HUMAS \\
\hline
\end{tabular}

Membantu dan bertanggung jawab kepada Kepala Sekolah dalam:

1. Mengatur dan menyelenggarakan hubungan sekolah dengan komite sekolah

2. Membina hubungan antara sekolah dengan wali murid

3. $\quad$ Membina pengembangan sekolah dengan lembaga pemerintah, dunia usaha dan industri, dan masyarakat

4. Melakukan koordinasi dengan semua staf untuk kelancaran kegiatan sekolah

5. Menciptakan hubungan yang kondusif diantara warga sekolah

6. Melakukan koordinasi dengan semua staf dan bertanggung jawab untuk mewujudkan $9 \mathrm{~K}$

7. Mempublikasikan seluruh kegiatan sekolah

8. Mewakili Kepala Sekolah apabila berhalangan untuk mnghadiri rapat masalah-masalah yang bersifat umum

9. Menyusun laporan secara berkala

10. Pengelolaan Sosial Media sekolah

Sumber: Arsip SLBN A Kota Bandung

Dalam praktiknya, pelayanan menggunakan komunikasi antarpribadi. Percakapan yang terjadi antara lembaga dengan publik akademik terjadi secara face to face. Dalam pelaksanaan kegiatan pelayanan, hubungan interpersonal selalu dihubungkan dengan komunikasi yang bersifat dua arah yaitu komunikasi antarpribadi. Keampuhan komunikasi antarpribadi adalah mengubah sikap, kepercayaan, opini dan perilaku komunikan sangat diperlukan oleh setiap Lembaga khususnya seorang Humas dalam memberikan pelayanan kepada publik. Komunikasi antarpribadi memungkinkan pelayanan yang diberikan untuk dipahami dan memahami oleh publiknya, karena komunikasi terjadi secara kontak langsung sehingga komunikator dapat menyentuh pribadi komunikan ketika pesan disampaikan, dan umpan balik berlangsung seketika sehingga komunikator mengetahui tanggapan komunikan atas pesan yang dasampaikan. Komunikasi antarpribadi atau komunikasi antarpersonal merupakan hal yang wajar dalam pola tindakan manusia, tetapi juga merupakan hal yang kompleks dan rumit dalam sebuah lembaga. Komunikasi menjadi sangat penting, karena dalam menjalin hubungan dengan publik akademik diperlukan adanya komunikasi yang baik (Yanti, 2013 :41)

Model komunikasi adalah deskripsi ideal tentang apa yang dibutuhkan untuk terjadinya komunikasi. Dengan demikian secara sederhana, model komunikasi dapat diartikan sebagai gambaran tentang variabel-variabel atau komponenkomponen komunikasi, dan hubungan antara variable-variabel atau komponenkomponen komunikasi tersebut (Hastasari \& Perwita, 2014 : 106).

Model komunikasi pelayanan di SLB Negeri A Kota Bandung berdasarkan dari hasil penelitian sebelumnya memiliki unsur komunikasi pada model komunikasi milik Lasswell, yaitu Source-MessageChanel-Receiver-Effect. Source adalah Tata usaha, Wakasek Humas, Kepala Sekolah, Koordinator Litbang dan Guru. Message yang disampaikan terdiri dari prosedur di antaranya: Menghubungi Tata Usaha (TU) bagi PPL/PPG/KKN, Surat Rekomendasi Dinas Pendidikan Provinsi 
Jawa Barat bagi peneliti, Disposisi Kepala Sekolah, Koordinasi Jadwal Lapangan, Mengkondisikan Objek, Pendampingan Publik Akademik oleh Penanggung Jawab/ Guru Pamong dan terakhir Menyerahkan Laporan Hasil Kegiatan.

Channel adalah saluran yang digunakan untuk berkomunikasi terbagi dua di antaranya komunikasi tatap muka yang terbagi dua juga yakni komunikasi antar personal dan komunikasi kelompok dan komunikasi bermedia adalah menggunakan aplikasi chatting whatsapp, surat menyurat dan telepon. Receiver adalah publik akademik yang dibagi kedalam dua yakni publik PPL/PPG/KKN dan publik penelitian/ observasi. Effect dilakukan oleh publik akademik dengan memberikan laporan penelitian ke SLBN A Kota Bandung.

Hingga saat ini, berbagai model komunikasi banyak dikembangkan dalam bidang kajian ilmu komunikasi. Model komunikasi S - R (Stimulus - Respon) misalnya, merupakan komunikasi yang membentuk aksi reaksi, komunikator lebih aktif memberikan stimulus (rangsangan), sementara komunikan/receiver berusaha memberikan respons (tanggapan). Selain itu, terdapat pula model komunikasi dua arah (two way communication) di mana kedua belah pihak yang terlibat dalam komunikasi sama-sama aktif dan kreatif dalam menciptakan arti terhadap ide atau gagasan yang disampaikan via pesan, sehingga jalannya komunikasi terkesan lebih dinamis dan komunikatif. Forsdale (1981) menyatakan bahwa salah satu model komunikasi yang tua tetapi masih digunakan orang untuk tujuan tertentu adalah model komunikasi yang dikemukakan oleh Harold Lasswell.

Terdapat beberapa unsur komunikasi pada model komunikasi milik
Lasswell, yaitu Source-Message-ChannelReceiver-Effect. Menurut Muhammad (2009), source disini adalah orang yang menyampaikan pesan (komunikator). Message adalah isi komunikasi atau pesan yang disampaikan dalam komunikasi tersebut. Isi yang dikomunikasikan ini kadang-kadang sederhana dan kadangkadang sulit dan kompleks. Channel adalah alat komunikasi (media), seperti surat, buku atau gambar. Receiver adalah orang yang menerima pesan dari komunikator. Terakhir, effect adalah tanggapan atau perubahan yang terjadi pada diri audiens setelah menerima pesan dari komunikator (Hastasari \& Perwita, 2014 : 106).

Terdapat beberapa unsur komunikasi dalam pelaksanaan model komunikasi pelayanan yang dapat digunakan oleh SLB Negeri A Kota Bandung, yaitu: SLB Negeri A Kota Bandung sebagai komunikator, Prosedur Pelayanan menjadi pesan yang akan diinformasikan ke publik. Serta publik akademik merupakan komunikan dimana publik akademik menerima pesan yang disampaikan oleh komunikator yakni SLBN A Kota Bandung. Dengan melihat tujuan penelitian ini, diperoleh model komunikasi milik Lasswell yang memiliki unsur-unsur komunikasi efektif. Unsur tersebut meliputi Source-MessageChannel-Receiver-Effect. Berikut gambar model komunikasi milik Lasswell.

Gambar Model komunikasi Lasswell

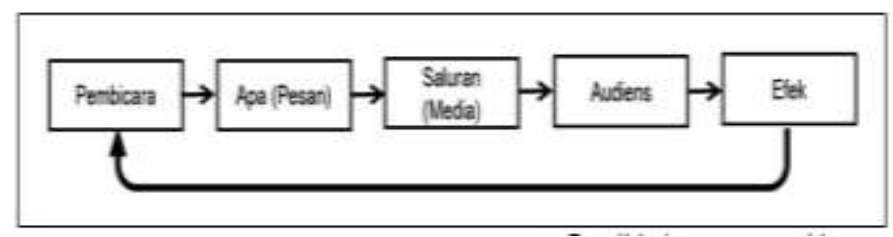

Sumber: (Muhammad, 2009) 
Perbedaan yang terdapat pada model komunikasi Lasswell dengan model komunikasi yang lain adalah adanya penggunaan media dan umpan balik. Yang dimaksudkan dengan media adalah alat komunikasi, seperti radio, televisi, surat, buku dan gambar. Namun yang perlu diperhatikan dalam hal ini adalah tidak semua media cocok untuk maksud pesan tertentu. Kadang-kadang suatu media lebih efisien digunakan untuk maksud tertentu tetapi untuk maksud yang lain tidak. Sedangkan yang dimaksud dengan efek di sini bisa berupa tanggapan atau perubahan yang terjadi pada diri audiens setelah menerima pesan. Akan tetapi perlu diingat bahwa kadang-kadang tingkah laku seseorang tidak hanya disebabkan oleh faktor hasil komunikasi tetapi juga dipengaruhi oleh faktor lain (Muhammad, 2009).

Tujuan pembagian publik akademik dikarenkan prosedurnya juga berbeda untuk masing-masing. Sehingga SLBN A Kota Bandung dapat dengan mudah melayani publik dengan tujuan kegitannya. Setiap publik akademik akan dilayani oleh SLBN A Kota Bandung tepatnya oleh Bagian Humas. Begitu juga dengan Pesan yang disampaikan dijelaskan tujuh prosedur yang harus dilakukan oleh publik akademik. Pesan ini penting dan harus dapat dipahami oleh publik akademik sebagai komunikan.

Peneliti juga memasukkan unsur umpan balik, karena peneliti menilai adanya umpan balik dari publik akademik. Umpan balik yang ditanggapi secara positif oleh SLBN A Kota Bandung diharapkan dapat menjadi indikator pemahaman prosedur pelayanan yang diberikan. Menurut (Liliweri, 2013 : 75) menyatakan bahwa peranan utama komunikator adalah untuk memengaruhi, yang dalam Bahasa psikologi-komunikasi disebut persuasi. Public relations dan ilmu komunikasi merupakan dua hal yang tak terpisahkan. Keduanya merupakan kesatuan dari dinamika kehidupan masyarakat. Kegiatan public relations adalah juga kegiatan komunikasi. Public relations merupakan salah satu bentuk kegiatan komunikasi yang dilakukan Lembaga atau organisasi dengan publik atau masyarakatnya. Untuk mewujudkan komunikasi dengan publik atau masyarakatnya (Suparmo, $2011: 1$ ).

Peran communication liaison adalah peran "perantara" bagi orang-orang Public Relations yang melayani Public Relations Manager tingkat atas dengan mengatasnamakan organisasi pada setiap ajang/pertemuan/program melalui macammacam pertemuan sejenis itu terbukalah kesempatan berkomunikasi bagi manajemen dan publiknya (internal maupun external) (Suparmo, 2011 : 45-46). Interaksi di antara tetangga bisa merupakan relasi sejajar dan saling menjaga kesopanan. Berbagai aturan yang terselubung bisa terbentuk dalam relasi/ hubungan pertemanan, partner bisnis, jalinan cinta, hubungan antar keluarga, atau hubungan lainnya, yang semuanya dapat berubah pada waktu pola interaksi juga berubah.

Dengan kondisi Bapak Yacobus Tri Bagio selaku Wakasek Humas SLBN A Kota Bandung yang tunanetra tidak dijadikan halangan untuk berkarir dan setara dengan yang lainnya dalam menjabat di sekolah. Berbeda dengan di Turki menurut Ismail (2008) dalam (Husain \& Shafrin, 2010 : 275) disebutkan bahwa prasangka sosial adalah salah satu elemen yang mengasingkan orang cacat dari kehidupan sosial di Turki di mana orang cacat berada dikecualikan dari bidang masyarakat, pendidikan, pekerjaan atau 
aktivitas budaya. Dia menambahkan bahwa kecacatan selalu terjadi sebuah fenomena yang dipersepsikan dengan prasangka. Adapun Maylynn and Eleanor (2006), mengatakan: penyandang cacat adalah manusia, dan sebagai manusia mereka tidak boleh disembunyikan karena mereka pantas mendapatkan semua upaya hak dan fasilitas bagi orang lain di komunitas (Husain \& Shafrin, 2010 : 275).

Pelayanan publik, berdasarkan UU no 25/2009,adalah tugas pokok institusi penyelenggara negara, termasuk lembaga pendidikan (Kriyantono, 2015). Kualitas manajemen pelayanan publik ditentukan oleh kapasitas seorang manajer dalam pengelolaannya, maka seorang manajer harus memiliki keterampilan dasar manajerial dalam mengelola sebuah organisasi (Permana \& Mahameruaji, 2018). Pengembangan kapasitas masih sering diabaikan khususnya oleh sekolah luar biasa. Hal ini dapat dilihat dari banyaknya masalah yang terjadi seperti masalah sumberdaya manusia, tatalaksana, dan sistem pelayanan pendidikannya (Zulfa, Noor, \& Ribawanto, 2015).

Hal ini tentu harus diantisipasi, sehingga pihak lembaga diharapkan mampu memberikan pelayanan kepada publiknya dengan baik, salah satunya dengan memberikan informasi yang akurat. Hal ini sejalan dengan pernyataan bahwa faktor yang paling dominan mempengaruhi kualitas layanan informasi akademik adalah faktor akurasi (Angkos, Rahmanto, \& Slamet, 2017). Akurasi informasi yang diberikan lembaga menjadi salah satu faktor penting untuk menghindari konflik dan publikasi yang tak diinginkan. Mengingat era digital sekarang ini membuka peluang publikasi yang dilakukan oleh publik atau warga melalui berbagai platform publikasi digital yang dikenal sebagai jurnalisme warga. Jurnalisme warga adalah praktik produksi dan penyebarluasan informasi yang berasal dari warga biasa yang disampaikan secara khas.(Eddyono, HT, \& Irawanto, 2019). Publikasi yang berasal dari warga ini dapat bersifat menguntungkan ataupun merugikan lembaga, jika tidak ditangani dengan baik.

\section{PENUTUP}

\section{Simpulan dan Saran}

Model komunikasi pelayanan publik akademik yang dilakukan SLBN A Kota Bandung sebagai berikut: Pihakpihak yang memberikan pelayanan kepada publik akademik adalah Tata usaha, Wakasek Humas, Kepala Sekolah, Koordinator Litbang dan Guru. Pesan yang disampaikan adalah mengenai prosedur komunikasi dalam pelayanan publik akademik yang memiliki tujuh tahapan. Media yang digunakan adalah komunikasi tatap muka (formal dan informal) serta komunikasi bermedia (Whatsapp, Telepon, Surat Menyurat dan Disposisi). Komunikan adalah publik akademik di antaranya mahasiswa, dosen, peneliti dan observer yang melakukan program PPL/PPG/PKL, penelitian tugas akhir (skripsi, tesis dan disertasi), penelitian non tugas akhir (hibah dan proyek). Umpan Balik dilakukan oleh publik akademik dengan memberikan laporan penelitian ke SLBN A Kota Bandung.

Berdasarkan data yang dimiliki sekolah, pada saat akhir penelitian publik akademik tidak menyerahkan hasil penelitian sesuai surat perjanjian. Oleh karena itu sebaiknya sekolah proaktif melakukan pemberitahuan sekaligus 
peringatan kepada publik akademik untuk menyerahkan hasil penelitian serta mensosialisasikan hasil penelitian tersebut agar pihak-pihak yang terlibat mengetahui mengenai kondisi Lembaga yang telah diteliti oleh publik akademik. Terdapat keluhan publik akademik mengenai objek penelitian yang bersikap tidak kooperatif dalam melakukan wawancara. Maka dari itu sebaiknya bersedia untuk memberikan keterangan. Agar data yang diberikan sesuai dengan yang di lapangan. Sehingga hasil yang didapatkan publik akademik akrat dan hasilnya dapat dipertanggungjawabkan.

\section{DAFTAR PUSTAKA}

Angkos, S. P., Rahmanto, A. N., \& Slamet, Y. (2017). Faktor-faktor yang mempengaruhi kualitas informasi pelayanan bidang akademik kepada mahasiswa. Jurnal Manajemen Komunikasi, 1(2), 234-264.

Ardianto, E. (2010). Metodologi Penelitian untuk Public Relations Kuantitatif dan Kualitatif. Bandung: Simbiosa Rekatama Media.

Creswell, J. W. (2013). Penelitian Kualitatif \& Desain Riset (Edisi 3). Yogyakarta: Pustaka Pelajar.

Eddyono, A. S., HT, F., \& Irawanto, B. (2019). Menyoroti Jurnalisme Warga: Lintasan Sejarah, Konflik Kepentingan, dan Keterkaitannya dengan Jurnalisme Profesional. Jurnal Kajian Jurnalisme, 3(1), 1. https://doi.org/10.24198/jkj.v3i1.217 62

Hastasari, C., \& Perwita, A. H. (2014). Pengembangan model komunikasi pelayanan untuk menghasilkan kader yang kreatif dalam menunjang keberhasilan program bina keluarga balita. Jurnal Komunikator, 6(2).

Husain, Z., \& Shafrin, N. (2010). Isolation : Willingness of Disabled Person to Integrate with its Community in the Context of Relationship after Disabled due to Accidents, 7(2), 274281.

https://doi.org/10.1016/j.sbspro.2010. 10.038

Kriyantono, R. (2015). Konstruksi Humas Dalam Tata Kelola Komunikasi Lembaga Pendidikan Tinggi di Era Keterbukaan Informasi Publik. Jurnal Pekommas, 18(2), 117-126.

Liliweri, A. (2013). Dasar-dasar Komunikasi Kesehatan. Yogyakarta: Pustaka Pelajar.

Littlejohn, S. W., \& Foss, K. A. (2016). Ensiklopedia Teori Komunikasi (Jilid 2). Jakarta: Kencana.

Muhammad, A. (2009). Komunikasi Organisasi. Jakarta: PT Bumi Aksara. Permana, R. S. M., \& Mahameruaji, J. N. (2018). Manajemen Sumber Daya Manusia Di Stasiun Televisi Lokal Radar Tasikmalaya Tv. ProTVF, 2(1), 1.

https://doi.org/10.24198/ptvf.v2i1.19 878

Rahmad, A. (2016). Manajemen Humas Sekolah. Media Akademi (1st ed.). Yogyakarta: Media Akademi.

slbnabandung.sch.id. (2018). Realita SeAbad SLB Negeri A Kota Bandung.

Suparmo, L. (2011). Aspek Ilmu Komunikasi dalam Public Relations. Jakarta: PT Indeks.

www.komisiinformasi.go.id.

Undang-undang sistem pendidikan nasional.

Yanti, D. N. P. (2013). Kualitas Komunikasi Pelayanan Customer Service Di PT. Indosat, Tbk Balikpapan. E-Journal Universitas 
JURNAL NOMOSLECA

Volume 5 Nomor 2, Oktober 2019

Mulawarman, 1(2), 39-54.

Zulfa, E. R., Noor, I., \& Ribawanto, H. (2015). Pengembangan Kapasitas Sekolah Luar Biasa Untuk Meningkatkan Pelayanan Pendidikan Bagi Anak Berkebutuhan Khusus (Studi Kasus di SDLBN Kedungkandang Malang). JAP (Jurnal Administrasi Publik), 2(3), 388-393. 